\title{
On the Convergence of Ishikawa Iterates to a Common Fixed Point for a Pair of Nonexpansive Mappings in Banach Spaces
}

\author{
Amit Singh And R.C. DimRI
}

\begin{abstract}
In the present paper we prove a common fixed point theorem for Ishikawa iterates of a pair of multivalued mappings on a Banach space, satisfying nonexpansive type condition which extend and generalize the results of Rhoades [16], [17] and others.
\end{abstract}

\section{Introduction AND PRELIMINARIES}

The Mann iterative scheme was invented in 1953, (see [9]) and was used to obtain convergence to a fixed point for many functions for which the Banach principle fails. For example, Rhoades [14] showed that, for any continuous self-map of a closed and bounded interval, the Mann iteration converges to a fixed point of the function.

In 1974, Ishikawa [4] devised a new iteration scheme to establish convergence for a Lipschitzian pseudo-contractive map in a situation where the Mann iteration process failed to converge. In recent years, a large literature has developed around the themes of establishing convergence of the Mann and Ishikawa for single-valued and multivalued mappings under various contractive conditions $[1,2,3,5]$ and others.

In the present paper, we prove a common fixed point theorem for Ishikawa iterates of a pair of multivalued mappings on a Banach space, satisfying nonexpansive type condition which extend and generalize the results of Rhoades [16], [17], Kubiaczyk and Ali [7], Rashwan[13] and others. To prove our result first we give the following results:

Theorem 1.1. [15] Let $T$ be a self-map of a closed convex subset $K$ of a real Banach space $(X, d)$. Let $\left\{x_{n}\right\}_{n=1}^{\infty}$ be a general Mann iteration of $T$ that converges to a point $p \in X$. If there exists the contstants $\alpha, \beta, \gamma \geq 0, \delta<1$

2000 Mathematics Subject Classification. Primary: 54H25; Secondary: 47H10.

Key words and phrases. Ishikawa-type iteration, Banach spaces, Multivalued nonexpansive mappings, Common fixed point. 
such that

$$
\begin{aligned}
\left\|T x_{n}-T p\right\| \leq & \alpha\left\{\mid x_{n}-p \|+\beta\left\{\mid x_{n}-T x_{n} \|+\gamma\left\{\mid p-T x_{n} \|\right.\right.\right. \\
& +\delta \max \left\{\left\{\mid p-T p \|,\left\{\mid x_{n}-p \|\right\},\right.\right.
\end{aligned}
$$

then $p$ is a fixed point of $T$.

If $T$ is continuous then Mann iterative process converges to a fixed point of $T$. But if $T$ is not continuous, then there is no guarantee that, even it the Mann process converges, it will converge to a fixed point of $T$.

If instead of the Mann iteration, we consider another iterative process, which is in some sense a double Mann iterative process, then it is possible to approximate the fixed point of some other classes of contractive mappings.

In a recent paper Rhoades [16] extended this generic theorem to the Ishikawa iteration process.

Theorem 1.2. [16] Let $K$ be a convex compact subset of a Hilbert space, $T: K \rightarrow K$ a Lipschtzin pseudo-contractive map and $x_{1} \in X$. Then the Ishikawa iteration $\left\{x_{n}\right\}$ defined as:

$$
x_{n+1}=\left(1-\alpha_{n}\right) x_{n}+\alpha_{n} T\left[\left(1-\beta_{n}\right) x_{n}+\beta_{n} T x_{n}\right],
$$

where $\left\{\alpha_{n}\right\}$ and $\left\{\beta_{n}\right\}$ are sequences of positive numbers satisfying:

(i) $0 \leq \alpha_{n} \leq \beta_{n} \leq 1, n \geq 1$,

(ii) $\lim _{n \rightarrow \infty} \beta_{n}=0$,

(iii) $\sum_{n=1}^{n \rightarrow \infty} \alpha_{n} \beta_{n}<\infty$,

converges strongly to a fixed point of $T$.

Chidume [2], Reich [19], Chang [1] and Deng and Ding [3] generalized the fundamental results related to Ishikawa iteration.

Throughout this paper let $(X, d)$ be a Banach space, $C B(X)$ the collection of closed, nonempty, bounded subsets of $X$ and $H(A, B)$ the Hausdroff metric on $C B(X)$.

The well known Hausdroff metric on $\mathrm{X}$ is defined as:

$$
H(A, B)=\max \left\{\sup _{a \in A} D(a, B), \sup _{b \in B} D(b, A)\right\}
$$

for any $A, B \in C B(X)$, where $D(a, B)=\inf _{b \in B} d(a, b)$

We shall need the following results.

Lemma 1.1 ([10]). If $A, B \in C B(X)$ and $a \in A$, then for $\epsilon>0$ there exists $b \in B$ such that $d(a, b) \leq H(a, B)+\epsilon$.

Let $K$ be a nonempty subset of $X$. The Ishikawa iteration scheme associated with two multivalued mappings $S, t: K \rightarrow C B(X)$ are defined as follows:

$$
\left\{\begin{array}{l}
x_{0} \in K \\
y_{n}=\left(1-\beta_{n}\right) x_{n}+\beta_{n} a_{n}, \quad a_{n} \in T x_{n} \\
x_{n+1}=\left(1-\alpha_{n}\right) x_{n}+\alpha_{n} b_{n}, \quad b_{n} \in S y_{n}
\end{array}\right.
$$


where (i) $0 \leq \alpha_{n}, \beta_{n} \leq 1$ for all $n$, additional conditionals will be placed $\left\{\alpha_{n}\right\}$ and $\left\{\beta_{n}\right\}$ as needed.

More recently Rhoades [17] proved a generic theorem for the Ishikawa iterates of a pair of multivalued mappings on a Banach space, and proved that the result has a number of corollaries. Rhoades [17] proved the following theorem.

Theorem 1.3. Let $X$ be a Banach space, $K$ is a closed, convex subset of $X$. $S$ and $t$ are multivalued mappings from $K$ to $C B(X)$. Suppose that the Ishikawa scheme (1), with $\left\{\alpha_{n}\right\}$ satisfying:

(i) $0 \leq \alpha_{n}, \beta_{n} \leq 1$ for all $n$,

(ii) $\liminf \alpha_{n}=d>0$ and $\left\{a_{n}\right\},\left\{b_{n}\right\}$, satisfying

$$
\left\|a_{n}-b_{n}\right\| \leq H\left(T x_{n}, S y_{n}\right)+\epsilon_{n} \text {, with } \lim \epsilon_{n}=0
$$

converges to a point $p$. If there exist non-negative numbers $\alpha, \beta, \gamma, \delta$ with $\beta \leq 1$ such that for all sufficiently large $n, S$ and $T$ satisfying

$$
H\left(T x_{n}, S y_{n}\right) \leq \alpha\left\|x_{n}-b_{n}\right\|+\beta\left\|x_{n}-a_{n}\right\|
$$

and

$$
\begin{aligned}
H\left(S p, T x_{n}\right) \leq & \alpha\left\|x_{n}-p\right\|+\gamma d\left(x_{n}, T x_{n}\right)+\delta d\left(p, T x_{n}\right) \\
& +\beta \max \left\{d(p, S p), d\left(x_{n}, S p\right)\right\}
\end{aligned}
$$

then $p$ is a fixed point of $S$. If also

$$
H(S p, T p) \leq \beta[d(p, T p)+d(p, S p)],
$$

then $p$ is a common fixed point of $S$ and $T$.

By using the above theorem, Rhoades proved the following corollaries.

Corollary 1.1. Let $X$ be a normed space, $K$ be a closed convex subset of $X$. Let $S, T: K \rightarrow C B(K)$ be mappings satisfying the following condition:

$$
\begin{aligned}
& H(T x, S y) \leq \\
& q \max \{k\|x-y\|,[D(x, T x)+D(y, S y)],[D(x, S y)+D(y, T x)]\}
\end{aligned}
$$

for all $x, y \in K$, where $k \geq 0$ and $0<q<1$.

If there exists a point $x_{0} \in K$ such that $\left\{x_{n}\right\}$, satisfying (1), (2), (i), (ii) and (iii) $\lim \beta_{n}=0$, converges to a point $p$, then $p$ is a common fixed point of $S$ and $T$.

Corollary 1.2. On the statement of Corollary 1.1, if we replace the condition (6) by

$$
\begin{gathered}
H(T x, S y) \leq q \max \left\{\|x-y\|, \frac{d(y, S y)[1+d(x, T x)]}{1+\|x-y\|},\right. \\
\left.\frac{d(x, S y)[1+d(x, T x)+d(y, T x)]}{2[1+\|1+x-y\|]}\right\}
\end{gathered}
$$

then $p$ is a common fixed point of $S$ and $T$. 
Now we prove the result for nonexpansive type condition for multivalued maps.

\section{MAin Result}

Theorem 2.1. Let $K$ be a nonempty, closed, convex subset of a Banach space $X$ and $T, S: K \rightarrow C B(X)$ satisfying

$$
H(T x, S y) \leq \max \{\|x-y\|,[d(x, T x)+d(y, S y)],[d(x, S y)+d(y, T x)]\}
$$

for all $x, y \in K$. If there exists an $x_{0} \in K$ such that a sequence $\left\{x_{n}\right\}$ satisfying (1), (2), (i), (ii) and (iii) $\beta_{n}=0$, converges to a point $p$, then $p$ is a common fixed point of $S$ and $T$.

Proof. To prove our result, it is sufficient to show that $S$ and $T$ Satisfy (3), (4), (5). Now by (8), we have

$$
\begin{aligned}
H\left(T x_{n}, S y_{n}\right) \leq \max \left\{\left\|x_{n}-y_{n}\right\|,\right. & {\left[d\left(x_{n}, T x_{n}\right), d\left(y_{n}, S y_{n}\right)\right], } \\
& {\left.\left[d\left(x_{n}, S y_{n}\right)+d\left(y_{n}, T x_{n}\right)\right]\right\} . }
\end{aligned}
$$

Also by (1), we have

$$
\left\{\begin{aligned}
\left\|x_{n}-y_{n}\right\| & =\beta_{n}\left\|x_{n}-a_{n}\right\|, \\
d\left(x_{n}, T x_{n}\right) & \leq\left\|x_{n}-a_{n}\right\|, \\
d\left(y_{n}, S y_{n}\right) & \leq\left\|y_{n}-b_{n}\right\|=\left\|y_{n}-x_{n}\right\|+\left\|x_{n}-b_{n}\right\| \\
& \leq \beta_{n}\left\|x_{n}-a_{n}\right\|+\left\|x_{n}-b_{n}\right\|, \\
d\left(x_{n}, S y_{n}\right) & \leq\left\|x_{n}-b_{n}\right\|, \\
d\left(y_{n}, T x_{n}\right) & \leq\left\|y_{n}-a_{n}\right\|=\left\|y_{n}-x_{n}\right\|+\left\|x_{n}-a_{n}\right\| \\
& \leq\left(1+\beta_{n}\right)\left\|x_{n}-a_{n}\right\| .
\end{aligned}\right.
$$

Now

$$
\begin{aligned}
& \leq\left\|x_{n}-a_{n}\right\|+\left\|y_{n}-b_{n}\right\| \\
& \leq\left\|x_{n}-a_{n}\right\|+\beta_{n}\left\|x_{n}-a_{n}\right\|+\left\|x_{n}-b_{n}\right\| \\
& \leq\left(1+\beta_{n}\right)\left\|x_{n}-a_{n}\right\|+\left\|x_{n}-b_{n}\right\| .
\end{aligned}
$$

Also

$$
\begin{aligned}
& \leq\left[\left\|x_{n}-b_{n}\right\|+\left\|y_{n}-a_{n}\right\|\right] \\
& \leq\left[\left\|x_{n}-b_{n}\right\|+\left(1+\beta_{n}\right)\left\|x_{n}-a_{n}\right\|\right] .
\end{aligned}
$$

Now using (10), (11) and (12) in (9), we have

$$
\begin{aligned}
H\left(T x_{n}, S y_{n}\right) \leq & \max \left\{\beta_{n}\left\|x_{n}-a_{n}\right\|,\left[\left(1+\beta_{n}\right)\left\|x_{n}-a_{n}\right\|+\left\|x_{n}-b_{n}\right\|\right],\right. \\
& {\left.\left[\left\|x_{n}-b_{n}\right\|+\left(1+\beta_{n}\right)\left\|x_{n}-a_{n}\right\|\right]\right\} } \\
\leq & \max \left\{\beta_{n},\left(1+\beta_{n}\right),\left(1+\beta_{n}\right)\right\}\left\|x_{n}-a_{n}\right\|+\left\|x_{n}-b_{n}\right\| .
\end{aligned}
$$


Using condition (iii), we have

$$
H\left(T x_{n}, S y_{n}\right) \leq\left\|x_{n}-a_{n}\right\|+\left\|x_{n}-b_{n}\right\| .
$$

It is clear that (3) is satisfied. Again by (8), we have

$$
\begin{array}{r}
H\left(T x_{n}, S p\right) \leq \max \left\{\left\|x_{n}-p\right\|,\left[d\left(x_{n}, T x_{n}\right)+d(p, S p)\right],\right. \\
\left.\left[d\left(x_{n}, S p\right)+d\left(p, T x_{n}\right)\right]\right\} \\
\leq \max \left\{\left\|x_{n}-p\right\|,\left[\left\|x_{n}-a_{n}\right\|+d(p, S p)\right],\right. \\
\left.\left[d\left(x_{n}, S p\right)+d\left(p, a_{n}\right)\right]\right\} .
\end{array}
$$

Since (3) is satisfied, therefore by (2), we have

$$
\begin{aligned}
\left\|x_{n}-a_{n}\right\| & \leq\left\|x_{n}-b_{n}\right\|+\left\|b_{n}-a_{n}\right\| \\
& \leq\left\|x_{n}-b_{n}\right\|+H\left(T x_{n}, S y_{n}\right)+\epsilon_{n} \\
& \leq\left\|x_{n}-b_{n}\right\|+\alpha\left\|x_{n}-b_{n}\right\|+\beta\left\|x_{n}-a_{n}\right\|+\epsilon_{n} .
\end{aligned}
$$

Since $\lim \left\|x_{n}-b_{n}\right\|=0$, we obtain

$$
\limsup \left\|x_{n}-a_{n}\right\| \leq \beta \lim \sup \left\|x_{n}-a_{n}\right\|
$$

since $0 \leq \beta \leq 1$, which implies

$$
\lim \left\|x_{n}-a_{n}\right\|=0 .
$$

Also

$$
\left\|p-a_{n}\right\| \leq\left\|p-x_{n}\right\|+\left\|x_{n}-a_{n}\right\| .
$$

From (14), (15) and (16), we have

$$
H\left(T x_{n}, S p\right) \leq\left\|x_{n}-p\right\|+\max \left\{d(p, S p), d\left(x_{n}, S p\right)\right\} .
$$

Therefore for all sufficiently large $n$, (4) is satisfied.

Since (3) and (4) are satisfied, then by Theorem 1.1, $p$ is a fixed point of $S$. Again by (8), we have

$$
h(T p, S p) \leq \max \{d(p, T p)+d(p, S p), d(p, S p+d(p, T p)\} .
$$

Hence (5) is satisfied,i.e. $p$ is a common fixed point of $S$ and $T$.

Corollary 2.1. Let $K$ be a nonempty, closed, convex subset of a Banach space $X$ and $T, S: K \rightarrow C B(X)$ satisfying

$$
\begin{aligned}
H(T x, S y) \leq \max \{\|x-y\| & , \frac{1}{2}[d(x, T x)+d(y, S y)], \\
& \left.\frac{1}{2}[d(x, S y)+d(y, T x)]\right\}
\end{aligned}
$$

for all $x, y \in K$. If there exists an $x_{0} \in K$ such that a sequence $\left\{x_{n}\right\}$ satisfying (1), (2), (i), (ii) and (iii) $\beta_{n}=0$, converges to a point $p$, then $p$ is a common fixed point of $S$ and $T$. 
Corollary 2.2. Let $K$ be a nonempty, closed, convex subset of a Banach space $X$ and $T, S: \rightarrow C B(X)$ satisfying

$$
\begin{aligned}
& H(T x, S y) \leq \max \{\|x-y\|, \frac{d(y, S y)[1+d(x, T x)]}{1+\|x-y\|}, \\
&\left.\frac{d(x, S y)[1+d(x, T x)+d(y, T x)]}{2[1+\|1+x-y\|]}\right\}
\end{aligned}
$$

for all $x, y \in K$. If there exists an $x_{0} \in K$ such that a sequence $\left\{x_{n}\right\}$ satisfying (1), (2), (i), (ii) and (iii) $\beta_{n}=0$, converges to a point $p$, then $p$ is a common fixed point of $S$ and $T$.

\section{REFERENCES}

[1] S.S. Chang, Some results for asymptotically pseudo-contractive mappings and asymptotically nonexpansive mappings, Proc. Amer. Math. Soc., 129(2001), 845-853.

[2] C.E. Chidume, Iterative approximation of fixed points of Lipschitz pseudo-contractive maps, Proc. Amer. Math. Soc., 129(2001), 2245-2251.

[3] L. Deng and X.P. Ding, Iterative approximation of Lipschitz strictly pseudo-contractive mappings in uniformly smooth Banach spaces, Nonlinear Anal., Theory Methods Appl., 24(1995), 981-987.

[4] S. Ishikawa, Fixed points by a new iteration method, Proc. Amer. Math. Soc., 44(1)(1974), 147-150.

[5] S. Ishikawa, Fixed points and iteration of nonexpansive mappings in a Banach space, Proc. Amer. Math. Soc., 59(1976), 65-71.

[6] R. Kannan, Some results on fixed points, III Fund. Math., 70(1971), 169-177.

[7] I. Kubiaczyk and N. Mostafa Ali, On the convergence of the Ishikawa iterates to a common fixed point for a pair of multivalued mappings, Acta Math. Hungar., 75(3)(1997), 253-257.

[8] Z. Liu, General principles for Ishikawa iterative process for multivalued mappings, Indian J. pure appl. Math., 34(1)(2003), 157-162.

[9] W.R. Mann, Mean value methods in iteration, Proc. Amer. Math. Soc., 4(1953), 506510.

[10] S.B. Nalder, Jr., Multivalued contraction mappings, Pecific J. Math., 30(1969), 475488.

[11] J.Y. Park and J.U. Jeong, Iteration processes of asymptotically pseudo-contractive mappings in Banach spaces, Bull. Korean Math. Soc., 38(2001), 611-622.

[12] R.A. Rashwan, On the convergence of Mann iterates to a common fixed point for a pair of mappings, Demonstratio Math., 23(1990), 709-712.

[13] R.A. Rashwan, On the convergence of Ishikawa iterates to a common fixed point for a pair of mappings, Demonstratio Math., 28(1995), 271-274.

[14] B.E. Rhoades, Fixed point iterations using infinite matrices, Trans. Amer. Math. Soc., 196(1974), 161-176.

[15] B.E. Rhoades, A common fixed point theorem for a sequence of fuzzy mappings, Internat. J. Math. \& Math. Sci., 3(1995), 447-450. 
[16] B.E. Rhoades, A general principle for Ishikawa iterations for multivalued mappings, Indian J. pure appl. Math., 28(8)(1997), 1091-1098.

[17] B.E. Rhoades, A general principle for Ishikawa iterations, 5th IWAA Proceedings.

[18] B.E. Rhoades, Iteration to obtain random solutions and fixed points of operators in uniformly convex Banach spaces, Soochow J. Math., 27(4)(2001), 401-404.

[19] S. Reich, Approximating fixed points of nonexpansive maps, Pan. America Math. J., 4(1994), 23-28.

\author{
Amit Singh \\ Department of Mathematics \\ H.N.B. Garhwal University \\ Post Box-100 Srinagar (Garhwal) Uttarakhand \\ INDIA-246174 \\ E-mail address: singhamit841@gmail.com
}

\title{
R.C. DimRi
}

Department of Mathematics

H.N.B. Garhwal University

Post Box-100 Srinagar (Garhwal) Uttarakhand

INDIA-246174

E-mail address: dimrirc@gmail.com 